\title{
Wondering about the future
}

\author{
Stephan Torre ${ }^{1}$ (D)
}

Accepted: 6 December 2021 / Published online: 31 December 2021

(C) The Author(s) 2021

\begin{abstract}
Will it rain tomorrow? Will there be a sea battle tomorrow? Will my death be painful? Wondering about the future plays a central role in our cognitive lives. It is integral to our inquiries, our planning, our hopes, and our fears. The aim of this paper is to consider various accounts of future contingents and the implications that they have for wondering about the future. I argue that reflecting on the nature of wondering about the future supports an Ockhamist account of future contingents according to which many of them are true. Alternative accounts which maintain that no future contingents are true, either by claiming that they are all false or by claiming that they are neither true nor false, face difficulties concerning why it is appropriate to wonder about them. Reflecting on wondering in general, and wondering about the future in particular, suggests that in wondering how the future will go, we implicitly assume that there is a determinate fact of the matter. After presenting an attractive account of interrogative attitudes that has been recently proposed by Jane Friedman and outlining some norms governing wondering, I argue that all accounts of future contingents except Ockhamism face difficulties concerning why it is appropriate to wonder about them.
\end{abstract}

Keywords Wondering $\cdot$ Future contingents $\cdot$ Ockhamism

\section{Introduction}

Will it rain tomorrow? Will there be a sea battle tomorrow? Will my death be painful? Wondering about the future plays a central role in our cognitive lives. It is integral to our inquiries, our planning, our hopes, and our fears. The aim of this

Stephan Torre

stephan.torre@gmail.com

1 University of Aberdeen, Aberdeen, UK 
paper is to consider various accounts of future contingents and the implications that they have for wondering about the future. I will argue that reflecting on the nature of wondering about the future supports an Ockhamist account of future contingents according to which many of them are true. Alternative accounts which maintain that no future contingents are true, either by claiming that they are all false or by claiming that they are neither true nor false, face difficulties concerning why it is appropriate to wonder about them. Reflecting on wondering in general, and wondering about the future in particular, suggests that in wondering how the future will go, we implicitly assume that there is a determinate fact of the matter. Oftentimes, alternatives to the Ockhamist account of future contingents are motivated by appeal to an asymmetry in our mental attitudes about the past and the future: the future is open and unknown in a way in which the past is not. I will argue that reflecting on wondering pulls in the opposite direction. Wondering about the future is much like wondering about the past or the present. Just as when we wonder whether it is presently raining in Glasgow, when we wonder whether it will rain tomorrow, we assume there is a true, yet unknown answer to the question that serves as the content of our wondering, and this is what makes our wondering about the future appropriate.

In the next section I briefly set up the problem of future contingents and summarize four different responses to the problem: Ockhamism, Falsism, Middlism, and Supervaluationism. In Sect. 3, I consider wondering in general and present an attractive account of interrogative attitudes that has been recently proposed by Jane Friedman. Following Friedman, I outline some norms governing wondering. In Sect. 4, I consider what implications the various responses to the problem of future contingents have for wondering about future contingents. I argue that all accounts except Ockhamism face difficulties concerning why it is appropriate to wonder about them.

\section{The problem of future contingents and responses}

As the name suggests, a future contingent statement is a statement that expresses a contingent proposition about the future. Discussions of future contingents and the open future tend to focus on a certain sub-set of contingent statements about the future: those considered to be presently unsettled. Typically, these are statements that involve a purportedly free action like:

(EGGS) Nicola will have eggs for breakfast tomorrow.

or a future event that is not determined by the past and present state of the world and the laws of nature like:

(NA24) This sodium-24 atom will decay in the next 24 h. ${ }^{1,2}$

\footnotetext{
1 Some define a future contingent as a statement that is about a future undetermined event. See Todd and Rabern (2021).

2 Sodium-24 is a radioactive isotope of sodium that has a 15-h half-life. Suppose here and throughout the rest of the paper that the demonstrative phrase 'this sodium-24 atom' in (NA24) succeeds in picking out a
} 
I am doubtful that a theoretically neutral and informative account can be given of what it is for a statement about the future to be presently settled or unsettled, but given that all parties to the debate seem to agree that statements like (EGGS) and (NA24) are the sort of statements at issue, I will focus on them as paradigm examples of future contingents in what follows. ${ }^{3}$

The problem of future contingents arises from considering whether they are true or false. Taking future contingents to be true or false raises the specter of fatalism. Consider the following representative argument that derives a fatalist conclusion from premises about whether a future contingent is true or false:

1. Either (EGGS) is true or (EGGS) is false.

2. If (EGGS) is true, then (EGGS) is true now. If (EGGS) is false, then (EGGS) is false now.

3. If (EGGS) is now true or (EGGS) is now false, then whether Nicola will have eggs for breakfast tomorrow is now inevitable.

4. Therefore, whether Nicola will have eggs for breakfast tomorrow is now inevitable. ${ }^{4}$

In this paper, I am not interested in evaluating this argument per se, but rather in looking at one of the implications of a popular response that involves rejecting Premise (1). Premise (1) follows from the Principle of Bivalence:

(Bivalence) Every proposition is either true or false (and not both).

I will divide approaches to future contingents into those that accept bivalence for future contingents and those that reject it. Two approaches that accept bivalence are Ockhamism and Falsism. The Ockhamist maintains that all future contingents are either true or false and accepts that many future contingents are true. ${ }^{5}$ The Ockhamist maintains that there is a single, actual future, where this is understood as the claim that for future contingents of the form 'It will be the case that $p$ ', either 'It will be the case that $p$ ' is true or 'it will be the case that not-p' is true. According to the Ockhamist, either it is true that there will be a sea battle tomorrow or it is true that there will not be a sea battle tomorrow. ${ }^{6}$ Statements involving 'will' are

\footnotetext{
Footnote 2 continued

specific atom of sodium-24 and that whether the atom will decay in the next $24 \mathrm{~h}$ is an indeterministic matter.

3 There are problems with interpreting settledness in terms of determinism. Discussions of the problems raised by future contingents have progressed independently of the determinism/indeterminism debate. Some think that a deterministic world can still have an open future, at least on some candidate ways of understanding what the openness of the future amounts to. And that statements about future indeterministic events can have determinate truth-values. See Torre (2011) for further discussion.

4 This argument is adapted from Markosian (1995). Similar arguments can be found in Barnes and Cameron (2009), Tooley (1997), and Diekemper (2007).

5 The Ockhamist, unlike the Falsist, endoreses Future Excluded Middle: Either it will be the case that $p$ or it will be the case that not $p$.

6 For the purposes of this paper, I take 'Ockhamism' to be a label for the view stated here: acceptance of bivalence for future contingents and there is a single, actual future in the sense outlined. The label 'Ockhamism' refers to different views in the future contingents literature.
} 
evaluated in much the same way as statements involving 'was'. If we take $\varphi$ to be an atomic formula and we take $F$ to denote the future-tense operator 'It will be the case 1 day hence' and ' $t+1$ ' to denote ' 1 day later than time $t$ ', then the Ockhamist maintains that:

- $F \varphi$ is true at $\mathrm{t}$ iff $\varphi$ is true at $\mathrm{t}+1$.

- $F \varphi$ is false at $\mathrm{t}$ iff $\varphi$ is false at $\mathrm{t}+1$.

So, on Wednesday, (EGGS) is true just in case Nicola has eggs for breakfast on Thursday. Various metaphysical accounts of time are compatible with the Ockhamist account of future contingents. What they have in common is that there is a single privileged way that things will go. One metaphysical account compatible with Ockhamism is the block universe, eternalist account according to which past, present, and future objects and events all exist in a non-branching block of spacetime. A theorist who adopts a branching metaphysics of the future could adopt Ockhamism assuming that there is one branch that is privileged over all the others, the branch that is, or represents, how things will actually go. ${ }^{7}$ Presentists and growing block theorists can also endorse an Ockhamist account of future contingents assuming they take there to be a single, privileged way that the future will go. ${ }^{8}$

Falsism also accepts bivalence, however unlike Ockhamism, denies that any future contingents are true. Broadly speaking, there are two distinct motivations for Falsism that have been defended in the literature. The first is that statements involving 'will' like (EGGS) and (NA24) are equivalent in meaning to modal statements like 'will definitely'. Arthur Prior puts forth this account calling it a 'Peircean' account after Charles Sanders Peirce. ${ }^{9}$ Discussing future contingents like (EGGS) and (NA24), Prior writes:

'Will' here means 'will definitely'; 'It will be that p' is not true until it is in some sense settled that it will be the case, and 'It will be that not p' is not true until it is in some sense settled that not-p will be the case. If the matter is not thus settled, both these assertions, i.e. [It will be the case that p] and [It will be the case that not p] are simply false...(Prior, 1967, 129).

Such a view claims that all future contingents are false precisely because future contingent statements amount to the claim that a contingent event in the future will definitely occur. Only claims about the future that are true in all ways the future may go, such as 'It will be the case that the sodium-24 atom decays or does not decay in the next 24 h' are true. The view upholds bivalence for future contingents because every future contingent is false and thereby either true or false. However, unlike the Ockhamist, it rejects Future Excluded Middle: either it will be the case that $p$ or it will be the case that not $p$, since both disjuncts are false.

\footnotetext{
7 This sort of view has been termed by Belnap and Green (1994) as the 'thin red line'

${ }^{8}$ What they take the truthmakers for future contingents to be is another matter. See Correia and Rosenkranz (2018) for an Ockhamist growing block account.

9 Although as Todd (2016) points out, C. S. Peirce didn't endorse the account.
} 
Falsism has most recently received a thorough defense by Patrick Todd. ${ }^{10}$ Todd, however, motivates Falsism using different reasons from those developed by Prior; he denies that 'will' statements are equivalent in meaning to 'definitely will' statements. Instead, Todd takes the inspiration for his view to be Bertrand Russell's analysis of sentences involving non-denoting definite descriptions like 'The present king of France is bald'. Famously, whereas Peter Strawson denies bivalence for such sentences claiming that they lack truth-value, Russell claims that they are false because they falsely claim the existence of a unique present king of France. ${ }^{11}$ Analogously, Todd claims that future contingent statements like (EGGS) and (NA24) are to be understood as presupposing a unique actual future. Todd states that "to say that something will happen (in this mode) is simply to say that it belongs to the unique actual future, not that the thing is determined to happen" (Todd, 2016, 787). So (EGGS) is to be analyzed as: There is a unique actual future in which Nicola has eggs for breakfast. Todd denies that there is a unique actual future and takes this denial to be required for preserving an open future. Since there is no unique actual future and part of the semantics of (EGGS) is that there exists a unique actual future, (EGGS) is false. All future contingents contain a false claim that there is a single actual future, and are thereby false.

I will consider two approaches that reject bivalence. One such approach is a three-valued logic approach perhaps most associated with Łukasiewicz (1930), and more recently defended by Tooley (1997) and Bourne (2004), that I will call Middlism. In a passage that clearly summarizes his approach to future contingents, Łukasiewicz writes:

I can assume without contradiction that my presence in Warsaw at a certain moment of next year, e.g. at noon on 21 December, is at the present time determined neither positively or negatively. Hence it is possible, but not necessary, that I shall be present in Warsaw at the given time. On this assumption the proposition I shall be in Warsaw at noon on 21 December of next year can at the present time be neither true nor false. For if it were true now, my future presence in Warsaw would have to be necessary, which is contradictory to the assumption. If it were false now, on the other hand, my future presence in Warsaw would have to be impossible, which is also contradictory to the assumption. Therefore the proposition considered is at the moment neither true nor false ... (Łukasiewicz 1930, 53).

This approach rejects bivalence for future contingents and also the Law of Excluded Middle which states that for every proposition, $p$, either $p$ or not- $p$. This approach introduces a third truth-value that I will call middle. Future contingents like (EGGS) and (NA24) are neither true nor false, but rather middle. Assigning an intermediate truth-value to such claims is intended to capture the idea that such statements are "at the present time determined neither positively or negatively" (Kukasiewicz 1930,

\footnotetext{
10 'Falsism' is my label for the view, not Todd's. Todd presents and defends the view in his (2016). Todd cites as precursors for Hartshorne (1941), Hartshorne (1964) and Prior (1967, 2003).

11 Russell (1905) and Strawson (1950).
} 
53). So the Middlist rejects Premise (1) of the above argument. The lesson to be learned from future contingents is that they are neither true nor false but instead possess an intermediate truth-value.

Perhaps the most popular approach to future contingents that rejects bivalence is Supervaluationism. ${ }^{12}$ A Supervaluationist approach to future contingents is most fully developed by Thomason (1970), Thomason (1984). Supervaluationism for future contingents is applied to a branching time model in which there are multiple distinct futures and furthermore no one future is privileged in any way over any other. Consider Fig. 1.

The branching model consists of histories: a history is a complete linear ordering of moments past, present and future; a particular tracing through the branching tree structure from trunk to branch tip. The diagram in Fig. 1 represents a branching future containing three distinct histories: h1, h2, and h3. Suppose $\mathrm{m} 1$ is a moment on Wednesday and we are considering what Nicola will have for breakfast tomorrow morning. In h1 she has Cheerios for breakfast, in h2 she has eggs, and in h3 she has porridge. Suppose Peter produces an utterance of (EGGS) at $\mathrm{m} 1$ on Wednesday. $\mathrm{m} 1$ is equally part of multiple histories: $\mathrm{h} 1, \mathrm{~h} 2$, and $\mathrm{h} 3$. Truth-values for future contingents are arrived at through a two-step process. ${ }^{13}$ The first step involves assigning satisfaction conditions to such statements relative to each history. This proceeds by applying tense-operators relative to each history in line with the Ockhamist account. If we take $\varphi$ to be an atomic formula and we take $F$ to denote the future-tense operator 'It will be the case 1 day hence' and ' $m+1$ in $h$ ' to denote ' 1 day later than moment, $m$, in history, $h$ ', then:

- $F \varphi$ is satisfied at $\mathrm{m}$ in $\mathrm{h}$ iff $\varphi$ is satisfied at $\mathrm{m}+1 \mathrm{in} \mathrm{h}$.

- $F \varphi$ is unsatisfied at $\mathrm{m}$ in $\mathrm{h}$ iff $\varphi$ is unsatisfied at $\mathrm{m}+1 \mathrm{in} \mathrm{h}$.

In our example, (EGGS) is satisfied in h2 and fails to be satisfied in h1 and h3 because Nicola has eggs for breakfast in h2 and not in h1 and h3. The second step of the process involves supervaluating over histories. A statement is true at $\mathrm{m}$ just in case it is satisfied in every history that contains $\mathrm{m}$ :

- $F \varphi$ is true at $\mathrm{m}$ iff for every $\mathrm{h}$ that contains $\mathrm{m}, F \varphi$ is satisfied at $\mathrm{m}$ in $\mathrm{h}$.

\footnotetext{
12 In addition to Thomason, I include Macfarlane (2003, 2008, 2014) under this label even though he adopts a Relativist account of future contingents. The reason I include him under the label of Supervaluationism for the purposes of this discussion is because the question we are considering is whether it is appropriate to wonder about a future contingent before the occurrence of the event described by the future contingent. Macfarlane's account relativizes truth of future contingents to a context of use and a context of assessment. The truth-value of a statement about the future is arrived at by supervaluating over all histories that include the context of use and the context of assessment. When the context of assessment coincides with the context of use, the truth-conditions for an utterance will be the same as the Supervaluationist truth-conditions, and so, to the extent that I think that Supervaluationism faces a problem regarding wondering about future contingents at the context of use, these problems apply equally to MacFarlane's account. Making truth of future contingents relative to context of use and context of assessment is intended to accommodate retrospective accuracy judgments: judgments after the event described in the utterance has occurred.

${ }^{13}$ Given the two-step process, there are various terminological choices that can be made in how to define the truth-predicate for Supervaluationism. My presentation follows Todd and Rabern's (2021, 104-105) presentation.
} 


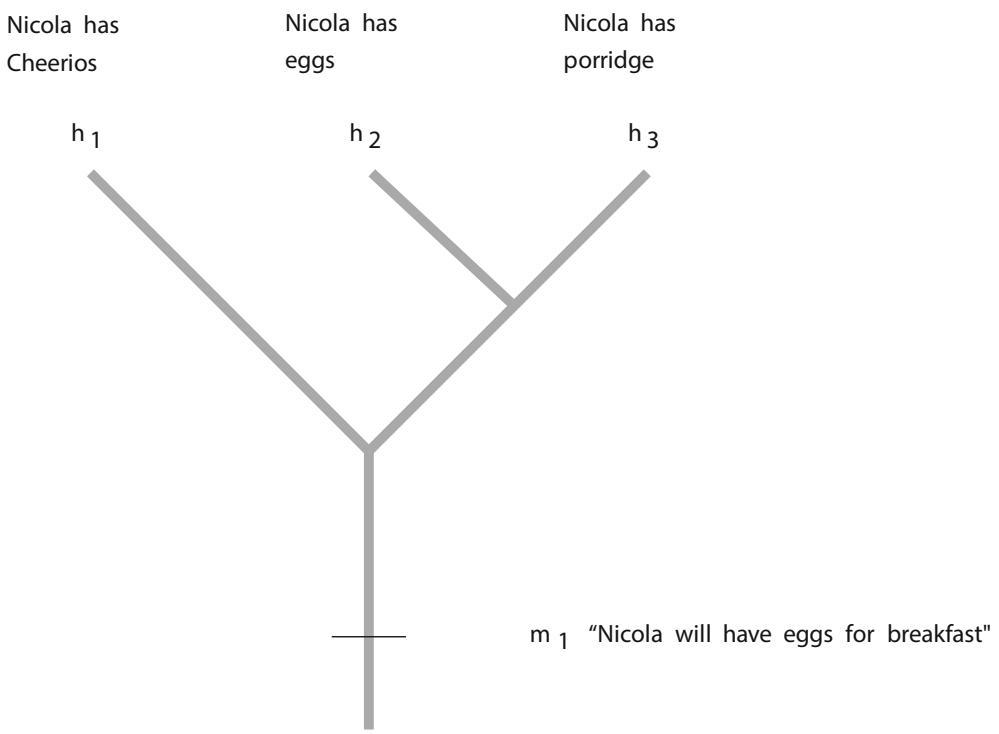

Fig. 1 Branching model

- $F \varphi$ is false at $\mathrm{m}$ iff for every $\mathrm{h}$ that contains $\mathrm{m}, F \varphi$ is unsatisfied at $\mathrm{m}$ in $\mathrm{h}$.

- Otherwise, $F \varphi$ is neither true nor false at $\mathrm{m}$.

In our example, the utterance of (EGGS) at $\mathrm{m} 1$ is neither true nor false since it is not satisfied at $\mathrm{m} 1$ in every history that contains $\mathrm{m} 1$ and not unsatisfied at $\mathrm{m} 1$ in every history that contains $\mathrm{m} 1$. It is satisfied at $\mathrm{m} 1 \mathrm{in} \mathrm{h} 2$ and unsatisfied at $\mathrm{m} 1$ in $\mathrm{h} 1$ and h3. Interestingly, even though the utterance of (EGGS) is neither true nor false at $\mathrm{m} 1$, an $\mathrm{m} 1$ utterance of 'Either Nicola will have eggs for breakfast tomorrow or it is not the case that Nicola will have eggs for breakfast tomorrow' is true at $\mathrm{m} 1$. It is true at $\mathrm{m} 1$ because it is satisfied by every history that contains $\mathrm{m} 1$. Future contingents are those statements that are satisfied in some histories and unsatisfied in others. So, all future contingents, like (EGGS) and (NA24), are neither true nor false on the Supervaluationist account. ${ }^{14}$

\footnotetext{
${ }^{14}$ Like the Middlist, the Supervaluationist maintains that future contingents are neither true nor false, but unlike the Middlist, also maintains that truth and falsity are the only truth-values. On Supervaluationism, future contingents are gappy rather than possessing a third truth-value. Another substantial difference between the two views is that, where $\varphi$ is a future contingent, $F \varphi \vee \neg F \varphi$ is true according to Supervaluationism, yet neither true nor false according to Middlism. This may well be seen as an advantage of the Supervaluationist approach to future contingents over the Middlist approach. Thanks to an anonymous referee for emphasizing these differences.
} 


\section{Wondering}

In this section I consider the psychological attitude of wondering whether, for example, wondering whether John Glenn flew in the Apollo 11 mission, wondering whether it is currently raining in Glasgow, or wondering whether there will be a sea battle tomorrow. ${ }^{15}$ I draw heavily on Jane Friedman's recent work on interrogative attitudes. I also outline some norms for wondering whether that follow on from her account.

According to Friedman (2013), wondering is one of several attitudes, like inquiring, investigating, and suspending judgment, that she calls 'interrogative attitudes'. She argues that such interrogative attitudes have questions as their contents. Consider the sentence 'Peter wonders whether Nicola will have eggs for breakfast tomorrow'. It is standard to take the interrogative complement 'whether Nicola will have eggs for breakfast tomorrow' to have a question as its semantic content. Friedman argues that, similarly, we should take the mental content of interrogative attitudes to be questions. Whereas the content of Moira's belief that it is raining in Glasgow is a proposition: that it is raining in Glasgow, the content of Aidan's wondering whether it is raining in Glasgow is not a proposition, but a question: Is it raining in Glasgow?.

What exactly are questions? There is no general agreement on the metaphysics of questions and fortunately, exactly what questions are need not concern us. I will follow Friedman in assuming that questions are not propositions (Friedman, 2013, 150). Some take questions to be sets of propositions, where the set of propositions consists of all the possible answers to the question. Others take questions to be open propositions. $^{16}$

Regardless of which metaphysical account of questions we adopt, we can introduce some basic features of questions and answers. Consider the following example questions:

A. Who flew in the Apollo 11 mission to the moon?

B. Did Barak Obama visit Cuba as president?

Questions have possible answers where answers can be understood as propositions. ${ }^{17}$ So the following are all possible answers to $A$ :

a. Neil Armstrong flew in the Apollo 11 mission.

b. Only Neil Armstrong, Michael Collins, and Buzz Aldrin flew in the Apollo 11 mission.

c. Fidel Castro flew in the Apollo 11 mission.

\footnotetext{
15 I will take the italicised wondering whether to denote the psychological attitude and will keep it unitalicised when using it in an interrogative phrase or sentence.

16 See Friedman (2013, 152-153) for discussion and references of various accounts of what questions are.

17 There is some debate over what sorts of entities answers can be. Some claim that answers can be individuals, and so Angela Merkel can serve as the answer to the question: Who is the current Chancellor of Germany? (e.g. Tichy, 1978). I will presuppose here that answers to questions are always propositions.
} 
We can distinguish between true and false answers to a question. Both $a$ and $b$ are true answers to $A$, and $c$ is a false answer to $A$. Furthermore, $a$ is a true partial answer to $A$, whereas $b$ is a true complete answer to $A: b$ completely and truly answers $A$ : it states that Neil Armstrong, Michael Collins and Buzz Aldrin flew in the Apollo 11 mission and no one else did. True, complete answers are the logically strongest true answers entailing all partial answers.

'Yes/No' questions like $B$ are called 'polar questions'. They have two possible answers. The phrase 'wonders whether' embeds either a polar question or a question with a finite number of possible answers. Consider the sentence 'Peter wonders whether Obama visited Cuba as president'. The semantic content of the 'wonders whether' phrase is a polar question: Did Obama visit Cuba as president? And the true complete answer to the question is the proposition that Obama visited Cuba as president. Wondering whether attitudes are just one species of wondering attitudes: we wonder why, wonder what, wonder when, wonder who, wonder where. In considering future contingents, I will focus on polar, wonders whether questions: wondering whether Nicola will have eggs for breakfast tomorrow and wondering whether the sodium-24 atom will decay in the next $24 \mathrm{~h}$.

Following Friedman, let us say that a question $Q$ is sound at world $w$ iff there is a proposition that truly and completely answers $Q$ at $w$ (Friedman, 2013, 151). Henceforth I will introduce the following notation: I will reserve uppercase italicized letters to denote questions and lowercase italicized letters to denote propositions. Where $Q$ is a question and $a$ is a proposition, I will use the notation ' $Q(a)$ ' to denote a true, complete answer to $Q$.

Friedman provides a compelling case for the existence of certain norms governing interrogative attitudes. At first pass, it seems problematic to claim that a subject knows $Q$ 's true, complete answer but continues to have an interrogative attitude with $Q$ as its content. For example it seems epistemically inappropriate to know that Obama visited Cuba as president and also to wonder whether Obama visited Cuba as president. Such cases are possible, for example, if I wonder where my keys are and then upon finding them in my coat pocket, I think to myself 'Silly me, I knew they were there!' Friedman notes, however that such cases are not 'epistemically happy' ones. ${ }^{18}$ These considerations motivate what she terms the Ignorance Norm (IN) for interrogative attitudes (here I've slightly modified it to take into account the notation I introduced for questions and their true, complete answers):

(IN) Necessarily, if one knows $Q(a)$ at $t$, then one ought not have an interrogative attitude towards $Q$ at $t$ (Friedman, 2017, 311).

\footnotetext{
18 Friedman $(2017,310)$. A complication arises when we consider Frege puzzle cases. For example, I may know that Hesperus is a planet, yet wonder whether Phosphorus is a planet and my wondering in such a case may seem appropriate. If we take the content of my knowledge to be a singular proposition containing Venus and the property of being a planet it seems that I know the true, complete answer to the question: Is Phosphorus a planet? I think there are ways of modifying (IN) to accommodate such cases, perhaps by taking into account the guise under which the true, complete answer is known. Alternatively, one could maintain that my wondering in such cases is indeed inappropriate, yet excusable.
} 
Given that my focus in this paper is on wondering whether with polar questions as their content, we can state an ignorance norm for wondering whether that is entailed by (IN) as follows:

(WIN1) Necessarily, if one knows $Q(a)$ at $t$, then one ought not wonder whether $Q$ at $t$.

(WIN1) seems very plausible. Wondering whether Obama visited Cuba as president is inappropriate in a case in which I know that Obama visited Cuba as president. It's possible for me to do both, but it's not an epistemically happy position to be in. Once I know the true, complete answer to the question, I ought to stop wondering whether Obama visited Cuba as president. ${ }^{19}$

In what follows, I will assume that if a proposition, $a$, is a true, complete answer to a question $Q$, then the proposition that $a$ is true is also a true, complete answer to $Q .{ }^{20}$ For example, if the proposition Obama visited Cuba as president is a true, complete answer to the question Did Obama visit Cuba as president?, then the proposition 'Obama visited Cuba as president' is true is also a true, complete answer to the question. ${ }^{21}$ So, applying (WIN1), if one knows 'Obama visited Cuba as president' is true, then one ought not wonder whether Obama visited Cuba as president. Similarly, if not- $a$ is a true, complete answer to a question $Q$, then the proposition that $a$ is false is also a true, complete answer to $Q$. For example, if the proposition that it is not currently raining in Glasgow is a true, complete answer to the question Is it currently raining in Glasgow? then the proposition 'It is raining in Glasgow' is false is also a true, complete answer to the question. In general, for polar, wonders whether questions, knowledge of the truth-value of the target proposition is knowledge of a true, complete answer to the question.

\footnotetext{
19 The 'ought' in (IN) and (WIN1) (as well as (WIN2) below) is to be understood as an epistemic 'ought' and my talk of wondering being appropriate or inappropriate here and throughout the paper is also to be understood in an epistemic sense. A potential worry: aren't there cases where one knows $Q(a)$ but it's nonetheless appropriate to wonder whether $Q$ ? Jay knows that he turned the stove off, yet he wonders whether he did, and goes back inside to double-check. Isn't Jay's double-checking epistemically virtuous? Might we praise his tendency to wonder despite knowing as beneficial in the long run, perhaps leading him to act appropriately on other occasions where he fails to know and indeed left the stove on? Friedman considers and replies to such worries in $(2017,312-313)$. She writes "There may be some sense in which it is epistemically appropriate to inquire despite knowing in some sorts of cases. My claim though is that there is some sense in which it is not. The subject who inquires while she knows will be doing something epistemically inappropriate, but not necessarily everything" (312).

${ }^{20}$ On some accounts of propositions, such as the possible worlds account, $a$ and $a$ is true may be the same proposition, in which case there is no need for a further assumption. For the purposes of this paper, I try to stay as neutral as possible regarding various accounts of what propositions are.

21 Here and in similar expressions in what follows, I take 'Obama visited Cuba as president' is true to be shorthand for The proposition expressed by 'Obama visited Cuba as president' is true.
} 


\section{Wondering about future contingents}

In what follows, I will consider the three alternatives to Ockhamism: Falsism, Middlism, and Supervaluationism, and argue that each faces difficulties in accounting for the appropriateness of wondering about future contingents.

\subsection{Falsism}

If we accept (WIN1) and we accept Falsism, then it follows that wondering about future contingents is inappropriate; we ought not wonder about them. To raise the stakes, suppose that an evil scientist tells me that he will torture me horribly for 5 days iff (NA24) is true and send me on a wonderful 5-days holiday iff (NA24) is false. Such a predicament would concern me greatly. I would undoubtedly lie awake at night wondering whether (NA24) is true or false. I would hope that it is false and fear that it is true. On the current framework, the question that serves as the content of my wondering is Will the sodium-24 atom decay in the next $24 \mathrm{~h}$ ? Let us call this question ' $N$ '.

Falsism seems to offer a therapy. In accepting the theory, I come to know that (NA24) is false. Falsism provides the true, complete answer to the question $N$. The true, complete answer is that It is false that the sodium-24 atom will decay within the next $24 \mathrm{~h}$. So, according to (WIN1) it is inappropriate for me to wonder whether the sodium-24 atom will decay. ${ }^{22}$ But I do continue to wonder, and my wondering certainly seems appropriate. This raises a problem for Falsism. ${ }^{23}$

It is useful to consider the reasons for why Falsists claim that future contingents are all false in order to get more insight into implications for wondering about future contingents like (NA24). Recall from Sect. 2 that Prior and Todd provide very different motivations for Falsism. Prior understands 'will' in statements like (NA24) to mean 'will definitely' or 'it is now settled that it will' and he contends that it is false that the sodium-24 atom will definitely decay in the next $24 \mathrm{~h}$ (and it is also

\footnotetext{
${ }^{22}$ This may overstate my epistemic position with respect to (NA24). In any case, in accepting Falsism, I ought to accept that (NA24) is false. If I believe outright that (NA24) is false, it also seems that I ought not wonder whether (NA24) is true or false. This follows from the attractive idea that to believe a proposition outright is to treat it as if one knows it (Williamson, 2000, 46-47). If I were to instead assign a high credence to Falsism, say .80, this seems compatible with wondering whether (NA24) is true or false, however it leads to other difficulties. In assigning a credence of .80 to Falsism, I should assign (at least) a credence of .80 to the proposition that (NA24) is false, and, assuming, as we are, that the evil scientist's promise is sincere, I should assign a credence of (at least) .80 to the proposition that I will go on holiday. The more confident I become of Falsism, the more confident I should be that I will go on holiday and avoid torture! I put aside the interesting question of what implications partial belief in Falsism and other theories of future contingents have for wondering about the future. Thank you to Uri Liebowitz and an anonymous referee for pressing this point.

23 Whereas I raise here a 'forward-looking' tension between Falsism and interrogative attitudes, an anonymous referee suggests a 'backwards-looking' tension as well. Suppose it is the next day and I learn that the atom has decayed. According to Falsism, yesterday's affirmative answer to the question Will the sodium-24 atom decay in the next $24 \mathrm{~h}$ ? was false (since it was then unsettled how things would turn out). But it seems problematic to claim both that the atom has decayed and yesterday's affirmative answer to the question Will the sodium-24 atom decay in the next $24 h$ ? was false. Thanks to the anonymous referee for this point.
} 
false that the sodium-24 atom will definitely not decay in the next $24 \mathrm{~h}$ ). Because the decay of the atom is entirely indeterministic, there are some futures in which it decays and some in which it does not. If Prior's Peircean analysis of future contingents is right, then given the indeterministic setup of our sodium-24 atom, we do know the true, complete answer to the question $N$; we know that it is not the case that the sodium-24 atom definitely will decay in the next $24 \mathrm{~h}$. So, according to (WIN1), we ought not wonder about (NA24). The fact that it is appropriate to wonder suggests that Prior's analysis mischaracterizes the content of our wondering: to wonder whether the sodium-24 atom will decay in the next $24 \mathrm{~h}$ is not to wonder whether it definitely will or whether it is now settled that it will. The fact that I can know now that it is not definite or settled that it will (or won't) decay, yet still wonder whether it will decay, strongly suggests that Prior's Peircean analysis of future contingents is wrong.

As noted above, Todd's defense of Falsism differs significantly from Prior's. Todd does not take the falsity of future contingents to be rooted in the fact that 'will' is equivalent in meaning to 'will definitely' or 'it is now settled that it will'. Rather he claims that 'will' statements presuppose the existence of a unique actual future. Todd claims that future contingent statements of the form 'It will be the case that $p$ ' are to be anaylzed as: 'The unique actual future features $p$ ' (Todd, 2016, 789). The reason that all future contingents are false on Todd's account is because it is false that there is a unique actual future. Following a Russellian analysis of non-denoting definite descriptions, it is false that there will be a sea battle tomorrow because it is false that there is a unique actual future that features one.

So, on Todd's analysis, to wonder whether the sodium-24 atom will decay in the next $24 \mathrm{~h}$ is to wonder whether the unique, actual future contains the decay of the sodium-24 atom. On our current framework, the question that serves as the content of my wondering whether attitude would be Does the unique actual future contain the decaying of the sodium-24 atom? Given Todd's commitment to the nonexistence of a unique actual future, the question falsely presupposes a unique actual future. With respect to questions like this, there are two approaches available: a Russellian approach and a Strawsonian approach. ${ }^{24}$ I will consider each and argue that both entail that if, as Todd claims, there is no unique actual future, then wondering about future contingents is inappropriate. Suppose Arthur wonders whether the present king of France is bald. Extending the Russellian analysis, the question that serves as the content of Arthur's interrogative attitude, Is the present king of France bald?, does have a true, complete answer. ${ }^{25}$ The true, complete answer is: There does not

\footnotetext{
24 As far as I know, neither Russell nor Strawson applied their theory of non-denoting definite descriptions to questions although I think the applications I suggest in what follows are natural extensions of their respective theories to the framework of interrogative attitudes that we are working with here.

25 The Russellian analysis faces a problem when applied to wondering whether attitudes containing nondenoting definite descriptions. This has been pointed out by Elbourne (2010). It seems that the Russellian analysis would take the content of Hans' wondering whether the ghost in the attic is making a mess to be the question: Is there a unique ghost in the attic and is it making a mess? But this seems to mischaracterize Hans' wondering. Hans isn't wondering whether there exists a unique ghost in his attic. If wondering whether attitudes raise a problem for the Russellian analysis of non-denoting definite descriptions, Todd's account inherits this problem. That Todd's account faces this problem has been
} 
exist a present king of France. ${ }^{26}$ Once Arthur learns that there is no present king of France, it is no longer appropriate for him to wonder whether the present king of France is bald. On the Russellian analysis, this inappropriateness follows from (WIN1), since learning that there is no present king of France involves learning the true, complete answer to the question. The same applies to wondering about future contingents on Todd's account. The question that serves as the content of my wondering about (NA24) has a true, complete answer: There does not exist a unique, actual future. In embracing Todd's account, I come to know the true, complete answer to the question that serves as the content of my wondering and so, by (WIN1), it is inappropriate for me to continue to wonder about it.

According to Strawson, the proposition that the present king of France is bald presupposes the proposition that the present king of France exists because if the former proposition is true or false, the latter proposition is true. Since the latter proposition is false, Strawson claims that the proposition that the present king of France is bald is neither true nor false. Extending the Strawsonian analysis to questions, the question that serves as the content of Arthur's interrogative attitude, Is the present king of France bald?, contains a false presupposition. Just as the statement The present king of France is bald is neither true nor false because it contains a false presupposition, the question Is the present king of France bald? lacks a true, complete answer and is thereby unsound. ${ }^{27}$ Suppose one learns that the question that serves as the content of one's wondering contains a false presupposition in the Strawsonian sense. Is it appropriate to continue to wonder about it? It seems that it is not. Friedman plausibly notes the inappropriateness of maintaining an interrogative attitude in cases where one learns that the question has a false presupposition. She writes:

To start, there are some cases in which suspension of judgment becomes epistemically inappropriate exactly when further inquiry does. The view being proposed here can give a straightforward explanation of those cases. For instance, say that at $\mathrm{w}$, the world of inquiry, $\mathrm{S}$ realizes that $\mathrm{Q}$ has some false presupposition or is similarly unsound, e.g., $\mathrm{Q}=$ What colour was Thomas Jefferson's Ferrari? (and w is the actual world). When $\mathrm{S}$ discovers that $\mathrm{Q}$ is faulty in this way, it looks as though further inquiry into $\mathrm{Q}$ would be irrational or otherwise epistemically inappropriate. But in this sort of case continuing to suspend about $\mathrm{Q}$ seems to be inappropriate as well, and in much the same way. If you know that Jefferson didn't have a Ferrari then suspending judgment

\section{Footnote 25 continued}

pointed out by Schoubye and Rabern (2017). But this problem is distinct from the one I highlight here. Here I assume the correctness of the analysis and show that it makes wondering about future contingents inappropriate.

26 On the Russellian analysis, what are the possible answers to the question that serves as the content of Arthur's wondering? It seems that there are three: there exists a present king of France and he is bald, there exists a present king of France and he is not bald, and there does not exist a present king of France. The last is the question's true, complete answer at the actual world.

27 A similar extension of the Strawsonian account of presupposition to questions is provided by Belnap and Steel $(1976,109-121)$. 
about what colour his Ferrari was looks inappropriate (Friedman, 2017, 315-316).

Here Friedman is discussing suspension of judgment, but I think the very same considerations apply to wondering whether. If I am wondering whether Thomas Jefferson's Ferrari was red and subsequently learn that my wondering contains a false presupposition, it seems inappropriate for me to continue to wonder whether Thomas Jefferson's Ferrari was red. These considerations motivate another norm for wondering whether: that it is inappropriate to wonder whether in cases where one learns that the question that serves as the content of one's wondering is unsound.

(WIN2) Necessarily, if one knows at that $Q$ is unsound, then one ought not wonder whether $Q$ at $\mathrm{t}^{28}$

In sum, if future contingents presuppose the existence of a unique actual future and no unique actual future exists, then it would be inappropriate to continue to wonder about them if we learn that there is no unique actual future. Following Todd's extension of the Russellian analysis of non-denoting definite descriptions, it would be inappropriate to continue to wonder about them because learning that there is no unique actual future involves learning their true, complete answer. If we instead adopt a Strawsonian analysis, it turns out that the questions that serve as the contents of our wonderings about future contingents are unsound, and in coming to know this, we ought not wonder about them. So if future contingents presuppose a unique actual future and no such future exists, once we accept this, it is no longer appropriate to wonder about them.

How might the Falsist respond? Perhaps they could respond that wondering about future contingents is fundamentally different than wondering about past and present propositions. Although (WIN1) and (WIN2) apply in the case of wondering about past and present propositions, they do not apply in the case of wondering about future contingents. Wondering about future contingents is a sui generis kind of wondering and has a distinctive normative profile. However, considerations motivating (WIN1) and (WIN2) for wondering about the past and present also motivate (WIN1) and (WIN2) for wondering about the future. An assertion of 'I know it is false that Biden will visit Cuba tomorrow and I wonder whether he will' sounds as bad as 'I know it is false that Biden visited Cuba yesterday and I wonder whether he did'. ${ }^{29}$ Similarly, the motivations for (WIN2) appear as strong for propositions about the future as they do for propositions about the past and the present. If I learn, contrary to what I had previously believed, that Biden will not buy a Ferrari, I should stop wondering what color Ferrari he will buy. Furthermore, there clearly seems to be something defective about knowing that there is no single actual future and continuing to wonder whether the single actual future contains the

\footnotetext{
${ }^{28}$ Perhaps this is too strong, although it could be restricted to questions that are unsound in virtue of containing a false Strawsonian presupposition in the sense outlined above.

${ }^{29}$ Friedman uses similar examples to motivate (IN). She writes that assertions like 'I know whether Bob went to the party, but I wonder whether he went' "sound awful" (Friedman, 2017, 309). Note that "I know whether Bob will go to the party, but I wonder whether he will" also sound bad. Cf. Fabrizio Cariani's discussion of what he terms "Future Might Contradictions" (Cariani 2021: 96-99).
} 
decay of the sodium-24 atom. Rather than finding evidence of a sui generis normative profile for wondering about future contingents, we instead find evidence to the contrary: that they are governed by the same norms.

Another way that the proponent of Falsism could respond is by claiming that I have mischaracterized the content of the relevant wondering whether attitudes. The semantics for future contingents is the Falsist semantics, but this need not mean that the content of wondering whether for future contingents is to be interpreted in this way. (NA24) is false, but when I wonder whether the sodium-24 atom will decay, the content of my wondering is not a question about the truth-value of (NA24); it is some other sound question such that I do not know its true, complete answer and it is thereby appropriate for me to wonder about it. This seems like a very unstable position. The question lurking in the background is: what is the content of the relevant question and why is there such a disconnect between the semantics for future contingents and the content of my wondering whether attitudes about them? ${ }^{30}$ To the extent that such considerations motivate adopting an alternative content for the relevant wondering whether attitude, they seem to also motivate adopting an alternative semantic content for future contingents. At the very least, it would be preferable for a theory to maintain that the semantic content of future contingents also serves as the target proposition of corresponding wondering whether attitudes concerning future contingents in the way that the semantic content of 'Obama visited Cuba as president' serves as the target proposition for Peter's wondering whether Obama visited Cuba as president. ${ }^{31}$

\subsection{Middlism}

Consider again the evil scientist's promise. Things are a bit different if we accept Middlism for future contingents because the evil scientist hasn't told me what he will do iff (NA24) is middle. Suppose he adds the following condition to his promise: he will leave me alone and do nothing iff (NA24) is middle; no torture, no holiday. Given this promise, I would wonder whether the sodium-24 atom will decay in the next $24 \mathrm{~h}$; I would fear that it will and hope that it will not.

Like Falsism, Middlism appears to offer a therapy: In accepting the theory, I come to know that (NA24) is middle and so I know the true, complete answer to the question that serves as the content of my wondering. And so, by (WIN1) I ought not wonder. But I do continue to wonder, and my wondering certainly seems appropriate. This raises a problem for Middlism.

The Middlist might respond that she is in a better position to respond to this difficulty than the Falsist. There are two general strategies that the Middlist might adopt in response. The first is to claim that when a true, complete answer to $Q$ is ' $a$ ',

\footnotetext{
30 If Moira asserts "it will rain tomorrow" and Aidan says "I wonder whether it will", it seems that Aidan is wondering about the very thing that Moira is asserting. The proponent of Falsism who responds in the way suggested here would need to deny this.

31 I haven't made precise what I take a target proposition for a wondering whether attitude to be but I think the following characterization suffices: For polar, wondering whether attitudes, proposition $p$ is a target proposition for wondering whether $Q$ just in case $Q(p)$ or $Q($ not- $p)$.
} 
is middle, it is still appropriate to wonder whether $Q$ and so (WIN1) needs to be revised: there are cases where one knows the true, complete answer to $Q$, yet it is still appropriate to wonder whether $Q$. It is precisely the nature of a proposition being middle that makes it indeterminate and thereby appropriate to wonder about the corresponding question. The second strategy is to claim that knowing that ' $a$ ' is middle does not involve knowing $Q$ 's true, complete answer. This strategy does not need to reject or revise (WIN1) since learning that a proposition is middle does not involve learning a question's true, complete answer.

It is worth noting that neither of these two strategies seem plausible when we consider other candidate propositions to which we might assign the truth-value middle. A natural such candidate would be in the case of vagueness. Suppose Larry is a borderline case of bald and suppose we adopt Middlism for vagueness and the truth-value of the proposition that Larry is bald is middle. Suppose that initially Susan doesn't know anything about how much hair Larry has; she's never met him or seen a picture of him. And so she wonders whether Larry is bald where the content of her wondering is the question L: Is Larry bald?. In such a case, Susan is aware of the possible, complete answers to $L$ but she does not know which of the possible, complete answers is the true answer. ${ }^{32}$ Suppose Susan then learns that 'Larry is bald' is middle. Both ways of responding mentioned in the previous paragraph seem implausible in light of Susan's new knowledge. If we grant that 'Larry is bald' is middle is the true, complete answer to $L$, it seems implausible to maintain that continuing to wonder is appropriate given this knowledge. In learning this proposition, Susan's inquiry has come to an end, just as if she had learned that 'Larry is bald' is true. There is nothing more to learn. There would be something defective were Susan to continue to investigate whether Larry is bald after learning that 'Larry is bald' is middle is the true, complete answer to L. The second strategy for responding also seems implausible. What grounds are there for denying that in knowing that 'Larry is bald' is middle Susan fails to know the true, complete answer to $L$ ? Presumably, the Middlist would agree that 'Larry is bald' is middle' is true. Could the Middlist deny that it is a complete answer? This seems implausible on a Middlist approach to vagueness. I think our concept of a complete answer to a question is tied to the concept of inquiry. In coming to know a complete answer, inquiry comes to an end. So to the extent that we think Susan's inquiry has come to an end in learning that 'Larry is bald' is middle, this suggests that 'Larry is bald' is middle is a complete answer to the question Is Larry bald? And so neither strategy seems plausible when considering a Middlist approach to vagueness.

Note how we would model Susan's initial wondering whether Larry is bald. It involves wondering which of the possible, complete answers: 'Larry is bald' is true, 'Larry is bald' is middle, 'Larry is bald' is false is the correct answer to L. And once Susan learns that 'Larry is bald' is middle, her inquiry comes to an end. But this model cannot be applied in the case of wondering about future contingents since,

\footnotetext{
32 Given that we are investigating whether wondering whether is appropriate on a given theory, let us suppose Middlism for vagueness and that Susan knows this is the correct account of vagueness. So the possible, complete answers are: 'Larry is bald' is true, 'Larry is bald' is false, and 'Larry is bald' is middle.
} 
once one accepts Middlism for future contingents, (NA24) is true and (NA24) is false are ruled out as possible answers to $N$. Just as coming to know that 'Larry is bald' is middle makes it inappropriate for Susan to continue to wonder whether $L$, coming to know that (NA24) is middle seems to make it inappropriate to continue to wonder whether $N$. Of course it is open to the Middlist to claim that wondering about future contingents is wholly different than wondering about vague propositions, but considering the case of vagueness suggests that wondering whether in cases of indeterminacy is plausibly understood as wondering what truth-value a given proposition has, and learning the truth-value renders further wondering inappropriate. The Middlist who insists that wondering about future contingents is appropriate would need to give this up: knowing what truth-value a proposition, $p$, has is compatible with wondering whether $p$. It is worth noting the oddity in accepting this. For a Middlist to wonder whether it will rain tomorrow is not for her to wonder whether it is true that it will rain tomorrow. She knows that it is not true that it will rain tomorrow, yet she wonders whether it will rain. ${ }^{33}$ An utterance of 'I know that it is not true that it will rain tomorrow and I wonder whether it will' certainly sounds defective, but should be assertable if knowing what truth-value a future contingent has is compatible with wondering about it. Furthermore, Middlists shouldn't hesitate to accept a bet that it is not true that it will rain tomorrow (and shouldn't hesitate to accept a bet that it is not false that it will). One might have thought that introducing an intermediate truth-value provides a way of modelling our ignorance of future contingents, but once we recognize that ignorance and wondering are plausibly understood as ignorance and wondering about what truthvalue a proposition has, we realise that introducing an intermediate truth-value undermines, rather than vindicates, our wondering about future contingents.

\subsection{Supervaluationism}

Let us again consider the evil scientist's promise. A natural way of understanding the promise on the Supervaluationist account is to take it as involving truth and falsity as defined on the account. Suppose the evil scientist promises that he will torture me iff (NA24) is true and send me on a holiday iff (NA24) is false. Given such a promise, wondering would clearly be inappropriate. Knowing that (NA24) is a future contingent, I know that it is satisfied in some histories and unsatisfied in others. So I know that (NA24) is not true, and so I know that I will not be tortured. ${ }^{34}$ And so understanding the promise in this way makes wondering about future contingents inappropriate.

How else might the Supervaluationist explain the appropriateness of wondering about future contingents? Interestingly, for a Supervaluationist, betting that the

\footnotetext{
33 This means rejecting the transparency of truth with respect to wondering: Assuming one has the concept of truth, wondering whether $p$ is to wonder whether $p$ is true. Kalderon $(1997,477)$ states the transparency of truth as entailing "if we posses the concept of truth, then in asserting, believing, inquiring after the proposition expressed by "S" we assert, believe, inquire after the proposition expressed by "It is true that $\mathrm{S}$ "."

34 By similar reasoning I can come to know that I will not be sent on a wonderful holiday.
} 
sodium-24 atom will decay tomorrow is not the same as betting that it is true that the sodium-24 atom will decay tomorrow. ${ }^{35}$ Given that (NA24) is a future contingent, a Supervaluationist would be foolish to take the second bet. What about the first? Given the nonequivalence between $\varphi$ and $\varphi$ is true, what if we take my wondering to be not whether it is true that the sodium-24 atom will decay tomorrow, but rather whether the sodium-24 atom will decay tomorrow? Given the Supervaluationist account of future contingents, would wondering be appropriate in this case?

Let us consider when wondering is appropriate given a Supervaluationist treatment of vagueness. Consider Susan's wondering whether Larry is bald. Initially, before she knows anything about Larry, her wondering is appropriate and this can be accommodated on the Supervaluationist framework by claiming that there are three possible, complete answers to her question L: 'Larry is bald' is true, 'Larry is bald' is false, and 'Larry is bald' is neither true nor false. The question is also sound since one of the possible, complete answers is true. Once Susan learns that Larry is a borderline case, her inquiry seems to come to an end, and given the Supervaluationist framework, it no longer seems appropriate for her to wonder whether Larry is bald. According to Supervaluationism, there is simply no further fact of the matter to uncover. That there is no fact of the matter makes it difficult to see how one could appropriately wonder about it. As Hartry Field notes "To put the matter more pointedly, the functional import of the notion of "no fact of the matter" is supposed to include this: for anyone who believes that there is no fact of the matter as to whether A, it would be pointless and misguided to wonder whether A, or to hope that A, or anything like that" (Field, 2015, 165). If we accept the Supervaluationist account of future contingents, then we are not in a situation like the one that Susan is initially in when she appropriately wonders whether Larry is bald. Rather we are in a situation like the one that Susan is in after she learns that Larry is a borderline case; all future contingents are borderline cases. There is simply no fact of the matter about whether the sodium-24 atom will decay tomorrow. Just as it seems inappropriate for Susan to continue to wonder whether Larry is bald once she learns that he is a borderline case and there is no further fact of the matter, so it seems inappropriate to wonder about future contingents once we accept that there is no further fact of the matter.

The Supervaluationist about future contingents may respond as follows: the indeterminacy involved in future contingents is of a fundamentally different sort than the indeterminacy involved in vagueness. ${ }^{36}$ Todd and Rabern endorse this line in a different context when they write, "The indeterminacy involved with the future involves a dynamic aspect that has no analogue with respect to vagueness - in the vagueness case, there is no "waiting around" to see how the indeterminacy gets

\footnotetext{
35 The Supervaluationist rejects the transparency of truth with respect to wondering (See footnote 33). However, unlike the Middlist, rejecting transparency for the truth-predicate is a bullet the Supervaluationist is already committed to biting.

36 A similar response could be given by the Middlist. However, I do not think it would succeed for reasons similar to those I provide against the Supervaluationist response below.
} 
resolved" (Todd and Rabern 2021, fn. 23) ${ }^{37}$. Belnap et al. (2001) provide a similar response to the challenge that wondering raises for their account of future contingents when they write:

It may seem that if at moment $m$ it is sensible to wonder whether $A$, then it must be that either $A$ is settled true at $m$, or that $A$ is settled false at $m$. More generally, it may seem that if one is to be able, at $m$, properly to raise the question whether $A$, then $A$ must be either settled true or settled false...No matter how things eventuate, the question posed on Monday, "Will there be a sea battle tomorrow?" will be answered. If there is a sea battle on Tuesday, then we may say, "The answer to the question is definitely 'yes'."; while if on Tuesday there is no sea battle, then we may say, "The answer to the question is definitely 'no'." We should therefore not reject the Monday question as badly posed. It is perfectly correct on Monday to say something like "We cannot yet provide a settled answer to that question, but must wait and see" (Belnap et al., 2001, 176).

The response seems to be that the fact that the indeterminacy will be resolved makes wondering about the target proposition appropriate. ${ }^{38}$ However, upon reflection, it becomes apparent that this response fails to move beyond the original difficulty of why it is appropriate to wonder about future contingents on the Supervaluationist account. Consider the initial worry concerning wondering about future contingents on the Supervaluationist account: the objector fails to see how the account renders it appropriate to wonder whether the sodium-24 atom will decay tomorrow. He notes that, according to the account, we can know that it is not true that it will, and we can know that it is not false that it will. Furthermore, just as it is inappropriate to continue to wonder whether Larry is bald once we learn that there is no fact of the matter about whether he is bald, so it is is inappropriate to wonder whether the sodium-24 atom will decay once we learn there is no fact of the matter about whether it will. The Supervaluationist then responds that in the case of future contingents it is appropriate to wonder because, unlike the vagueness case, there will be a determinate fact of the matter. But if the objector has trouble seeing how it is appropriate to wonder whether the sodium-24 atom will decay tomorrow, he will also have trouble seeing how it is appropriate to wonder what the determinate fact of the matter will be. ${ }^{39}$ In fact, wondering whether the sodium-24 atom will decay, on

\footnotetext{
37 As an anonymous referee for this journal points out, it is not the case that the indeterminacy of all future contingents will be resolved. Suppose that 'Jesus will return someday' expresses a future contingent, time never ends, and for every future time, $t$, Jesus fails to return at $t$. In such a case, there is no future time at which the indeterminacy of the future contingent gets resolved. This example is based on one that Barnes and Cameron $(2011,5)$ consider and reply to.

38 However this doesn't help with future contingents like the one mentioned in footnote 37 . It seems that one could appropriately wonder whether Jesus will return someday even in a world in which time never ends and Jesus never returns.

39 It is worth noting that if we take the content of the wondering attitude to be the question What will the determinate fact of the matter be?, it appears to have two possible complete answers: It will be true that the sodium-24 atom decays tomorrow and It will be false that the sodium-24 atom decays to tomorrow. However, neither of these possible, complete answers to the question are true. Rather, they are neither
} 
the Supervaluationist account, seems indistinguishable from wondering what the determinate fact of the matter will be. So one who has difficulty in understanding why wondering about the former future contingent is appropriate on the account will also have difficulty understanding why wondering about the latter future contingent is appropriate on the account. This "wait and see" response answers the challenge of why wondering about future contingents is appropriate by offering up another future contingent, and thereby fails to make progress in explaining why it is appropriate to wonder about them.

\subsection{A general non-ockhamist response?}

There is a general reply to the problem I have raised for wondering about the future that is similar in spirit to the one just considered and is available to all three nonOckhamist views discussed above. The reply involves maintaining that true, complete answers to questions concerning future contingent events change over time. ${ }^{40}$ Knowing the present, true, complete answer to a question about a future contingent event does not make it inappropriate to have the question as the content of one's wondering attitude. Given that a true, complete answer to the question can change, one can appropriately wonder what the true, complete answer will be even if one knows what the true, complete answer presently is. The main problem raised by WIN1 for wondering about future-contingents can be avoided by modifying WIN1 as follows (where ' $\mathrm{t} 1$ ' and ' $\mathrm{t} 2$ ' denote distinct times):

(WIN1*) Necessarily, if $Q$ is a question pertaining to time $t 2$ and one knows at $t 1$ a true, complete answer-at- $t 2$ to $Q$, then one ought not wonder at $t 1$ whether $Q .^{41}$

Consider the case in which I wonder on Monday whether the sodium-24 atom will decay in the next $24 \mathrm{~h}$. The suggestion is that (WIN1*) is compatible with the appropriateness of my wondering because I fail to know the true, complete answerat-Tuesday to the question of whether the sodium-24 atom decays.

However, I do not think this response succeeds, for similar reasons to those given in reply to the "wait-and-see" response above. According to the current framework, wondering whether involves one having a question as the content of one's attitude. According to the response at hand, what might we take the question that serves as

\footnotetext{
Footnote 39 continued

true nor false since they are satisfied in some of the relevant histories and unsatisfied in others. Given that neither of the possible, complete answers are true, the corresponding question is unsound. So if we take the question that serves as the content of the wondering to be What will the determinate fact of the matter $b e$ ? and accept Supervaluationism for future contingents, wondering would be inappropriate in virtue of violating (WIN2). No progress has been made in taking this question as the content of the wondering.

40 The reply being considered here commits its proponent to the interrogative analogue of temporalism for propositions. According to temporalism, a proposition like the poker is hot is true at some times and false at other times, rather than being true (or false) eternally. Temporalism for questions would be the view that questions have true, complete answers relative to times, and what serves as a true, complete answer to a question at one time may not serve as a true, complete answer at another time.

${ }^{41}$ I thank an anonymous referee for suggesting this general line of response and this modified version of (WIN1).
} 
the content of my wondering to be? Presumably, it is a question about the answer-atTuesday to the question Does the sodium-24 atom decay?. We might state it as follows: What will the answer-at-Tuesday be to the question 'Does the sodium-24 atom decay?'. But this question is itself a question concerning a future contingent: I wonder of the question Does the sodium-24 atom decay? what its true, complete answer-at-Tuesday will be. The response answers the challenge of why it is appropriate to wonder about future contingents by offering up another future contingent which faces the same difficulties as the original. To see this, note that, according to the non-Ockhamist accounts considered above, I can know on Monday that the true, complete answer-at-Tuesday to Does the sodium-24 atom decay? is not The sodium-24 atom decays because if it were, then it would be true on Monday that the sodium-24 atom will decay, and all three non-Ockhamist theories deny this. So again, this response does not seem to make progress in explaining why it is appropriate to wonder about future contingents on these non-Ockhamist accounts.

Here is another way of stating the problem with this non-Ockhamist response. Presumably, the proponent of this response would accept the following biconditional (where ' $o$ ' denotes an object, ' $F$ ' denotes a property and ' $t$ ' denotes a future time):

- It will be the case that $o$ is $F$ at $t$ iff a true, complete answer-at- $t$ to the question Is $o F$ at $t$ ? is that $o$ is $F$ at $t$.

To reject such a biconditional would suggest that the account fails to provide a correct analysis of will-claims. However, in accepting this biconditional, it becomes clear that the right-hand side inherits the same difficulties that the left-hand side faces with respect to wondering about the future. Consider the Falsist, for example. She claims that in the case of future contingents, the left-hand side of the biconditional is false and so, in accepting the biconditional, she commits herself to maintaining that the right-hand side is false as well. This leaves us with the same problem with respect to wondering about future contingents that was raised in section 4.1: If one knows that it is false that the true, complete answer-at- $t$ to the question $I s o F$ at $t$ ? is that $o$ is $F$ at $t$, why is it appropriate to wonder about it? Noting the non-Ockhamist's commitment to the above biconditional shows that the proposed response does not make progress in explaining the appropriateness of wondering about future contingents.

\subsection{Ockhamism}

Ockhamism stands in sharp contrast to the three accounts considered above in that it allows for a straightforward and uniform treatment of wondering about future contingents and wondering more generally. Friedman's framework seamlessly extends to future contingents and treats them in the same way as wondering about past and present events. Furthermore, and central to the goal of this paper, it explains why wondering about future contingents is appropriate. Suppose there was another sodium-24 atom on May 14, 1984 and I now wonder whether it decayed before midnight on May 15, 1984. The content of my wondering whether attitude is 
the question: Did the sodium-24 atom decay on May 15, 1984? and it has two possible complete answers: It decayed on May 15, 1984 and It did not decay on May 15, 1984. Furthermore, it has a true, complete answer and so the question is sound. In being ignorant of the true, complete answer, my wondering is appropriate. Wondering about future contingents like (NA24) is given the same treatment. It has two possible complete answers and one of them is true. My ignorance about the true, complete answer makes my wondering appropriate.

One might respond "But isn't there an asymmetry between the past and the future? Isn't the past fixed and the future open? So, shouldn't there be an asymmetry in wondering about the future versus wondering about the past?" I agree that there are various asymmetries between the past and the future, and some underlie an asymmetry in mental attitudes, but it is not clear that there is such an asymmetry in our wondering whether attitudes. Relief, regret, anticipation, and fear are all plausibly temporally asymmetric attitudes. For example, if Susan regrets not sending Mia a card for her birthday, and then learns that Mia's birthday is not until next month, it is inappropriate for her to continue to regret not sending Mia a card for her birthday (even if Susan knows she is bad about sending cards and knows she will not send her one next month). But wondering whether doesn't seem to be temporally asymmetric in this way. The following three considerations support the conclusion that wondering whether attitudes about future events are much like wondering whether attitudes about past and present events. The first is that in the case of temporally asymmetric attitudes like relief and anticipation, learning how we are temporally related to the event in question has a significant impact on the attitude. This does not seem to be the case for wondering whether. We can wonder whether a particular event occurs without knowing (or caring) whether the event is in our future. Discovering that the event lies in our future does not appear to affect our wondering whether attitude in the way that it does with other temporally asymmetric attitudes like relief and anticipation. Suppose Wanda wonders whether Serena Williams wins the 2021 US Open. Due to her preoccupation with other things and the disarray of the tournament calendar due to Covid, Wanda is unaware of whether the 2021 US Open has already taken place. Finding out that the 2021 US Open hasn't happened yet does not alter her attitude of wondering whether Serena Williams wins. It would be entirely appropriate for her to continue to wonder whether Serena Williams wins were she to discover that the 2021 US Open hasn't happened yet. In contrast, it would have a significant impact on her attitude of anticipation of the event: learning that it hasn't happened yet may lead her to adopt an attitude of anticipation towards the event.

A second related consideration is that cases of past + future wondering seem natural and unproblematic in a way that would be surprising if our attitude of wondering about the future was significantly different than our attitude of wondering about the past or present. By past + future wondering I have in mind cases of wondering about a proposition that is in part about the past and in part about the future. Consider a farmer who is away from home and at midday wonders whether it rains back home today. For the sake of his crops, he wonders whether today contains rain. The interval that he wonders about is in part in his past and in part in his future. If wondering about the future was fundamentally different than 
wondering about the past, we would expect such cases of past + future wondering to be problematic or at least awkwardly disjunctive; but they don't seem to be. Contrast this with the oddity of the farmer at midday adopting the attitude of anticipation towards today containing rain. He might anticipate news that it rained at some point today, but anticipating rain today, when the day is already half over, seems odd.

Thirdly, the same considerations that motivate (WIN1) and (WIN2) in the case of wondering about the past and present also apply to wondering about the future, suggesting that wondering about the future has the same normative profile as past and present wondering. As noted previously, an assertion of 'I know that James will attend the party and I wonder whether he will' sounds defective in a similar way in which 'I know that James attended the party and I wonder whether he did' does. Furthermore, knowing that a question about the future is unsound makes it inappropriate to wonder about it in the same way that knowing a question about the past is unsound makes it inappropriate to wonder about it. Knowing that the party this evening has been cancelled makes it inappropriate to wonder whether James will attend, just as knowing that the party last night was cancelled makes it inappropriate to wonder whether James attended. That the same norms seem to apply to wondering about the future as to wondering about the past and present further suggests that there is no deep temporal asymmetry in our wondering whether attitudes. These considerations suggest that it is appropriate to wonder about the future in just those conditions in which it is appropriate to wonder about the past: when there is a true, complete answer to the question that serves as the content of our wondering and we are ignorant what the true complete answer is. Only Ockhamism can render wondering about the future appropriate in the same way as wondering about the past and present.

\section{Conclusion}

So what does this reflection on wondering about future contingents establish? I think reflecting on the nature of wondering whether involves an implicit assumption that the question that serves as the content of the attitude is sound: the question has a true, complete answer and wondering whether is appropriate only if we fail to know what the true, complete answer is. Ockhamism, unlike the other accounts of future contingents that we considered, vindicates our wondering about the future by entailing that our interrogative attitudes about the future are sound, and the account doesn't allow us to deduce their true, complete answer. Oftentimes, alternatives to the Ockhamist account of future contingents are motivated by appeal to an asymmetry in our mental attitudes about the future; the openness and uncertainty of the future requires a rejection or modification of bivalence. But I hope to have shown that reflecting on wondering pulls in the opposite direction. When we wonder about the future, we assume that there is an unknown, yet true answer to our question, and this is what makes our wondering about the future appropriate. The alternatives to Ockhamism considered here have difficulty accommodating these aspects of wondering. Of course, nothing I have said here provides an argument for 
the conclusion that Ockhamism is true. It may well be that the metaphysics of time is such that no future contingents are true and one of the alternative accounts considered above is correct. If that's the case, then our natural tendency to wonder about the future is epistemically inappropriate.

Acknowledgements I would like to thank Phillip Bricker, Jane Friedman, Andrea Iacona, Uri Leibowitz, Paula Sweeney, Patrick Todd, Brandt van der Gaast, Clas Weber, the audience of the Stirling Philosophy Visiting Speaker Seminar, and the Aberdeen Philosophy Work-in-Progress group for very helpful discussion and feedback on earlier drafts. Additionally, the comments from the two anonymous referees for this journal were very helpful and substantially improved this paper.

\section{Funding None}

Availability of data and material Not applicable

Code availability Not applicable

\section{Declarations}

Conflict of interest The author declare that Stephan Torre have no conflict of interest.

Open Access This article is licensed under a Creative Commons Attribution 4.0 International License, which permits use, sharing, adaptation, distribution and reproduction in any medium or format, as long as you give appropriate credit to the original author(s) and the source, provide a link to the Creative Commons licence, and indicate if changes were made. The images or other third party material in this article are included in the article's Creative Commons licence, unless indicated otherwise in a credit line to the material. If material is not included in the article's Creative Commons licence and your intended use is not permitted by statutory regulation or exceeds the permitted use, you will need to obtain permission directly from the copyright holder. To view a copy of this licence, visit http:// creativecommons.org/licenses/by/4.0/.

\section{References}

Barnes, E., \& Cameron, R. (2009). The open future: Bivalence, determinism and ontology. Philosophical Studies, 146, 291-309.

Barnes, E., \& Cameron, R. P. (2011). Back to the open future. Philosophical Perspectives, 25(1), 1-26. https://doi.org/10.1111/j.1520-8583.2011.00206.x

Belnap, N., \& Green, M. (1994). Indeterminism and the thin red line. Philosophical Perspectives, 8, 365-388.

Belnap, N., Perloff, M., \& Xu, M. (2001). Facing the future: Agents and choices in our indeterminist world. Oxford University Press.

Belnap, N. D., \& Steel, T. B. (1976). The logic of questions and answers. Yale University Press. GoogleBooks-ID: SCxuQgAACAAJ.

Bourne, C. (2004). Future contingents, non-contradiction, and the law of excluded middle muddle. Analysis, 64(2), 122-128.

Cariani, F. (2021). The modal future: A theory of future-directed thought and talk. Cambridge University Press

Correia, F., \& Rosenkranz, S. (2018). Nothing to come: A defence of the growing block theory of time. Springer.

Diekemper, J. (2007). B-theory, fixity, and fatalism. Nous, 41(3), 429-452.

Elbourne, P. (2010). The existence entailments of definite descriptions. Linguistics and Philosophy, 33(1), 1-10. 
Field, H. (2015). Mathematical undecidables, metaphysical realism, and equivalent descriptions. In R. E. Auxier, D. R. Anderson, \& L. E. Hahn (Eds.), The philosophy of Hilary Putnam (pp. 145-172). Open Court.

Friedman, J. (2013). Question-directed attitudes*. Philosophical Perspectives, 27(1), 145-174. https:// doi.org/10.1111/phpe. 12026

Friedman, J. (2017). Why suspend judging? Nous, 51(2), 302-326. https://doi.org/10.1111/nous.12137

Hartshorne, C. (1941). Man's vision of god, and the logic of theism (Vol. OCLC, p. 1456831). Willett, Clark \& Co.

Hartshorne, C. (1964). Deliberation and excluded middle. Journal of Philosophy, 61(16), 476-477.

Kalderon, M. E. (1997). The transparency of truth. Mind, 106(423), 475-497.

Łukasiewicz, J. (1930). Philosophical remarks on many-valued systems of propositional logic. In S. McCall (Ed.), Polish logic 1920-1939 (1967, pp. 40-65). Oxford: Clarendon Press.

MacFarlane, J. (2003). Future contingents and relative truth. The Philosophical Quarterly, 53(212), 321-336. https://doi.org/10.1111/1467-9213.00315

MacFarlane, J. (2008). Truth in the garden of forking paths. In M. Garcia-Carpintero \& M. Kolbel (Eds.), Relative truth (pp. 81-102). Oxford University Press.

MacFarlane, J. (2014). Assessment sensitivity: Relative truth and its applications. Oxford University Press.

Markosian, N. (1995). The open past. Philosophical Studies, 79(1), 95-105.

Prior, A. (1967). Past, present and future. Oxford University Press.

Prior, A. N. (2003). Time and modality. Clarendon Press. Google-Books-ID, K5nymD8qgigC.

Russell, B. (1905). On denoting. Mind, 14(56), 479-493.

Schoubye, A. J., \& Rabern, B. (2017). Against the Russellian open future. Mind, 126(504), 1217-1237.

Strawson, P. F. (1950). On referring. Mind, 59(235), 320-344.

Thomason, R. H. (1970). Indeterminist time and truth-value gaps1. Theoria, 36(3), 264-281. https://doi. org/10.1111/j.1755-2567.1970.tb00427.x

Thomason, R. H. (1984). Combinations of tense and modality. In D. Gabbay \& F. Guenthner (Eds.), Handbook of philosophical logic: Extensions of classical logic (Vol. II, pp. 135-165). Springer.

Tichy, P. (1978). Questions, answers, and logic. American Philosophical Quarterly, 15(4), 275-284.

Todd, P. (2016). Future contingents are all false! On behalf of a Russellian open future. Mind, 125(499), 775-798.

Todd, P., \& Rabern, B. (2021). Future contingents and the logic of temporal omniscience. Noûs, 55(1), $102-127$.

Tooley, M. (1997). Time, tense, and causation. Oxford University Press.

Torre, S. (2011). The open future. Philosophy Compass, 6(5), 360-373. https://doi.org/10.1111/j.17479991.2011.00395.x

Williamson, T. (2000). Knowledge and its limits. Oxford University Press.

Publisher's Note Springer Nature remains neutral with regard to jurisdictional claims in published maps and institutional affiliations. 